\title{
Suction conditions for minimizing the production of free hemoglobin during blood salvage using an autotransfusion apparatus
}

\author{
Sang-Bum An, Eun Su Choi, and Wonsik Ahn \\ Department of Anesthesiology and Pain Medicine, College of Medicine, Seoul National University, Seoul, Korea
}

Background: Three kinds of conditions should be considered to reduce free hemoglobin production using an autologous cell salvage device. They are the negative suction pressure, the size of suction tip, and the air contact during suction. We want to examine which condition is the most important factor to produce free hemoglobin.

Methods: One pack of red blood cell and one pack of fresh frozen plasma with the same blood type were mixed. They were aspirated based on the two suction pressure $(-150 \mathrm{mmHg}$ or $-300 \mathrm{mmHg})$, three sizes of suction tips, and the two conditions of air contact, in which the suction tip was located in the surface of blood or in the middle of the blood. Seven $\mathrm{ml}$ sized EDTA tube was used to collect $5 \mathrm{ml}$ blood. All the procedure repeated ten times. Free hemoglobin, total hemoglobin, and hematocrit were measured. Hemolysis ratio was calculated with following formula. Hemolysis ratio = (new free hemoglobin production $) \times(100$-hematocrit $) /$ (total hemoglobin $)$.

Results: Free hemoglobin production and hemolysis ratio were increased when the suction tip was positioned in the surface than when it was in the middle of the blood. The pressure of negative suction and three kinds of the suction tips did not influence the production of free hemoglobin nor the hemolysis ratio.

Conclusions: The air contact is the most important factor to reduce hemolysis using autologous cell salvage device. Suction pressure or suction tip diameter have little influence to produce hemolysis. (Korean J Anesthesiol 2011; 60: 266-271)

Key Words: Autologous blood transfusion, Cell salvage, Hemoglobin, Toxicology.

Received: September 3, 2010. Revised: October 27, 2010. Accepted: October 27, 2010.

Corresponding author: Wonsik Ahn, M.D., Department of Anesthesiology and Pain Medicine, College of Medicine, Seoul National University, 101, Daehang-no, Jongno-gu, Seoul 110-744, Korea. Tel: 82-2-2072-3087, Fax: 82-2-766-3087, E-mail: aws@snu.ac.kr

This research was supported by a grant 09142KFDA466 from Korea Food \& Drug Administration in 2009.

(c) This is an open-access article distributed under the terms of the Creative Commons Attribution Non-Commercial License (http:// creativecommons.org/licenses/by-nc/3.0/), which permits unrestricted non-commercial use, distribution, and reproduction in any medium, provided the original work is properly cited. 


\section{Introduction}

Perioperative autotransfusion includes preoperative blood donation, acute normovolemic hemodilution, postoperative blood salvage and reinfusion of the salvaged blood using an autotransfusion apparatus [1]. Most of autotransfusion can only be used in a limited number of patients. Preoperative blood donation requires sufficient hematopoiesis and a patient with a status that can tolerate anemia [2]. Acute normovolemic hemodilution can be used in patients with a hematocrit level of $\geq 28 \%$ [1]. Although some investigators have reported that postoperative blood salvage is safe and effective [3], others have been concerned about blood clotting disorders due to the unwashed salvaged blood $[4,5]$. Reinfusion of the salvaged blood using an autotransfusion apparatus has a wider range of applications than other methods. It is frequently used in children [6] and in patients who refuse transfusion [7], and the cost of this is low [8]. However, postoperative complications have sometimes been reported [9]. The free hemoglobin $(\mathrm{Hb})$ is removed after combining it with haptoglobin or hemopexin [10]. However, if the quantity of the free $\mathrm{Hb}$ is excessive, it can cause nephrotoxicity and abnormalities of vascular constriction [11]. Therefore, numerous studies on the complications involved with salvaged blood have been carried out.

To suppress the production of free $\mathrm{Hb}$, many investigators have recommended reducing the negative suction pressure [12] and using a suction tip with a relatively great diameter [1]. It is well known that large quantities of free $\mathrm{Hb}$ are produced under strong shearing forces, and so more free hemoglobin is produced with the increasing contact with air [13]. Although many factors are involved in the production of free $\mathrm{Hb}$, there have been few comparative studies of these factors. Therefore, this study was conducted to determine which factors significantly affect the production of free $\mathrm{Hb}$ by comparing the suction conditions, including the negative suction pressure, the shape of a suction tip and the extent of the blood's contact with air.

\section{Materials and Methods}

This study was approved by the Institutional Review Board of our hospital (No. 0908-009-060). In addition, the study was performed with the protocol approved and the blood supplied by the Blood Center, the Republic of Korea National Red Cross. The blood was collected from blood donators, and it was identified to be infected with hepatitis virus or human immunodeficiency virus, and this infected blood does not meet the criteria for human use. The blood was stored for 30 days with citrate phosphate dextrose adenine-1, which is an anticoagulant.

All the experiments were performed in the operating room that was maintained at $22-23^{\circ} \mathrm{C}$. In total, 10 units of packed red blood cells and 10 units of fresh frozen plasma were used.

One unit of packed red blood cells and 1 unit of fresh frozen plasma of the same blood cell type were mixed in a 500$\mathrm{ml}$ beaker. The baseline levels of $\mathrm{Hb}$ and free $\mathrm{Hb}$ and the hematocrit were measured using $5 \mathrm{ml}$ of the mixture in an EDTA tube. A 7-ml EDTA tube was connected to 2 tubes using a 3-way stop-cock, with one tip being connected to a suction tip and the other being connected to a pressure gauge on the wall (Fig. 1).

In this experiment, the negative pressure ranged between 150 and $300 \mathrm{mmHg}$, which was controlled by using a negative pressure gauge (Vacutron ${ }^{\circledR}$, Allied Healthcare Products, Inc, St. Louis, MO, USA) [12]. Negative pressure was applied for 1.2 seconds at $150 \mathrm{mmHg}$ and for 1.1 seconds at $300 \mathrm{mmHg}$. We used 3 kinds of suction tips. Suction tip 1 was a $23-\mathrm{cm}$ straight tip with a 2 -mm-diameter end hole and two 2-mm-diameter side holes. Suction tip 2 was a $25-\mathrm{cm}, 70$-degree curved tip with a $2-\mathrm{mm}$-diameter end hole. Suction tip 3 was a $33-\mathrm{cm}$, 20-degree curved tip with a 4-mm-diameter end hole and five 2-mm-diameter side holes (Fig. 2). All the experiments were performed under one of 2 conditions: (1) all the suction holes were soaked in the blood and (2) half of each suction hole was soaked in the blood and the remaining half was exposed to air.

In each setting, 5-ml of blood was suctioned. After each suction, the suction tip was cleansed by irrigation with 50$100 \mathrm{ml}$ of normal saline. Using the same mixture of packed red blood cells and fresh frozen plasma, the experiments were performed in combined sessions with 2 different negative pressures, 3 different kinds of suction tips and 2 immersion conditions for exposure to air (for a total of 132 experiment sessions). The free $\mathrm{Hb}$, the total $\mathrm{Hb}$, the hematocrit and the hemolysis rate were measured in each mixture. After the mixture collected in an EDTA tube was centrifuged at 3,500 rpm

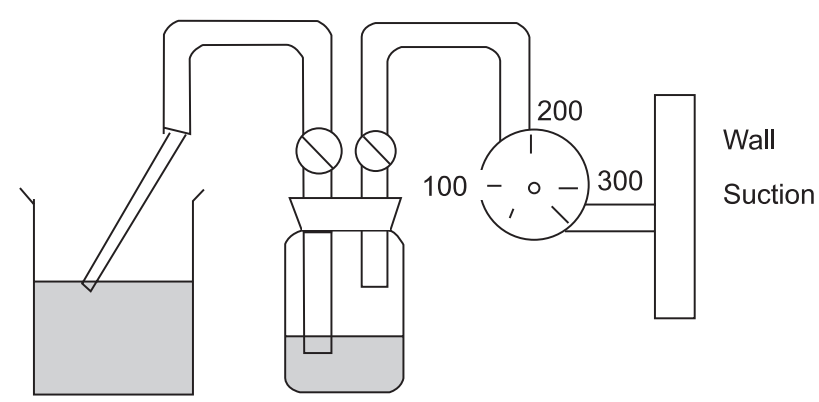

Fig. 1. Schematic drawing of the experiment design. The suction tip was completely or partially immersed in the blood. Three kinds of suction tips were used (Fig. 2). The pressure gauge was set at -150 or $-300 \mathrm{mmHg}$. Seven-milliliter EDTA tubes were used to collect $5 \mathrm{ml}$ of suctioned blood. Two 3-way stop-cocks were used to control the start of the suction. 

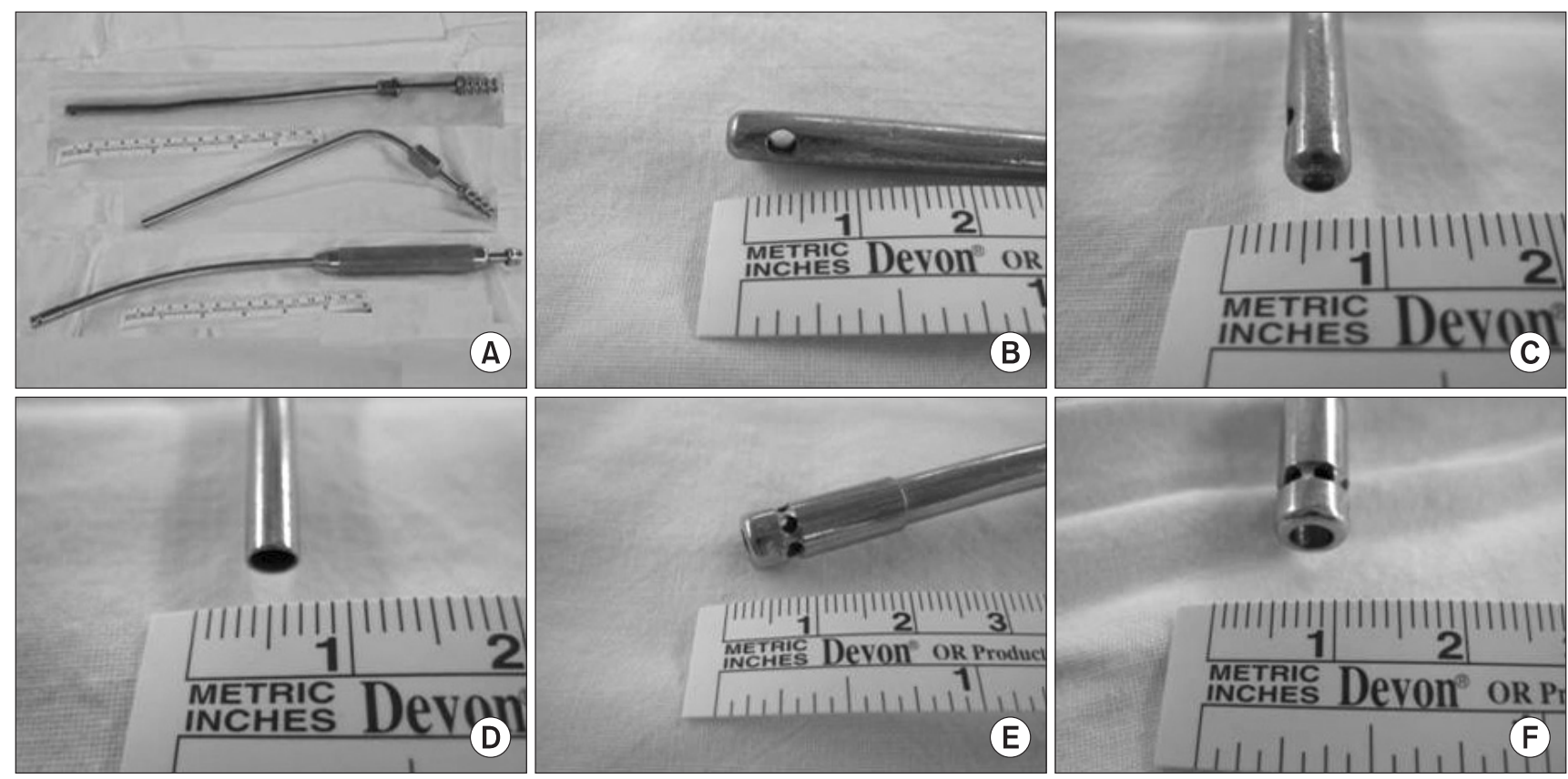

Fig. 2. Three kinds of suction tips. (A) Suction tip 1 is straight (bottom). Suction tip 2 is sharply curved (middle). Suction tip 3 is slightly curved (top). (B, C) Suction tip 1 has 1 end hole and 2 side holes. (D) Suction tip 2 has only 1 end hole. (E, F) Suction tip 3 has 1 large end hole and 5 small side holes.

for 5 minutes, $10 \mu \mathrm{l}$ of supernatant was taken and diluted in 1 $\mathrm{ml}$ of plasma $\mathrm{Hb}$ buffer. The free $\mathrm{Hb}$ of this sample was analyzed using a spectrophotometer (U-2000 ${ }^{\circledR}$, Hitachi-Hitech, Tokyo, Japan).

The free $\mathrm{Hb}$, the total $\mathrm{Hb}$ and the hematocrit were measured, and then the hemolysis rate was calculated for each experiment session. The hemolysis rate was calculated using the following formula [12]: hemolysis ratio $=\left(\mathrm{fHb}_{\mathrm{A}}-\mathrm{fHb}_{\mathrm{B}}\right) \times$ (100-hematocrit $\left.{ }_{B}\right) /\left(\mathrm{Hb}_{\mathrm{B}}\right)$ where $\mathrm{Hb}=$ hemoglobin, $\mathrm{fHb}=$ free hemoglobin, $\mathrm{A}=$ postsuction and $\mathrm{B}=$ presuction.

The hemolysis rate is expressed without a unit, the free $\mathrm{Hb}$ as $\mathrm{mg} / \mathrm{dl}$, the total $\mathrm{Hb}$ as $\mathrm{g} / \mathrm{dl}$ and the hematocrit as a percentage.

Comparisons of the mean values between the 2 groups were done using the t test, and the Wilcoxon rank sum test was applied when the data was not normally distributed. Comparisons of the means among the 3 groups were done using ANOVA. Multiple comparisons were done using the Turkey test, and the Friedman test was also applied when this was not appropriate. A P value of $<0.05$ was considered statistically significant. A repetition frequency of 11 was determined at a detectability rate of $80 \%$ based on the baseline values measured before the start of this experiment.

\section{Results}

The baseline values of the free $\mathrm{Hb}$, the total $\mathrm{Hb}$ and the hematocrit were $27.3 \pm 10.5 \mathrm{mg} / \mathrm{ml}, 13.4 \pm 0.7 \mathrm{~g} / \mathrm{dl}$ and $39.2 \pm$
$1.9 \%$, respectively. The free $\mathrm{Hb}$, the hemolysis rate, the total $\mathrm{Hb}$ and the hematocrit were independently analyzed for the 3 suction conditions. The free hemoglobin level was significantly higher for the surfaced suction tip than for the soaked suction tip. (86.9 \pm 26.3 versus $32.418 .0 \mathrm{mg} / \mathrm{dl}$, respectively; $\mathrm{P}<0.001)$, and the hemolysis rate was also significantly higher for the surfaced suction tip than for the soaked suction tip $(2.7 \pm 1.2$ versus $0.2 \pm 0.8$, respectively; $\mathrm{P}<0.001$ ) (Fig. 3). The free $\mathrm{Hb}$ level was constant, regardless of the different negative suction pressures (150 and $300 \mathrm{mmHg}$ ) and the different kinds of suction tips (suction tips 1, 2 and 3) (P > 0.05).

After 1 or 2 suction conditions was fixed, the data of the remaining suction conditions was averaged. These averages were designated with the names of the remaining suction condition. For instance, the "150 mmHg" condition indicated that measurements with 3 different suction tips and 2 immersion conditions (completely and partially immersed suction tips) were averaged in the $150 \mathrm{mmHg}$ suction pressure. The $150 \mathrm{mmHg}+$ a completely immersed tip suction condition indicated that the measurements taken with 3 different suction tips were averaged in the " $150 \mathrm{mmHg}$ suction pressure + completely immersed tip." The free $\mathrm{Hb}$ and hemolysis rates were significantly different between the completely and partially immersed tips $(\mathrm{P}<0.001$, Table 1). The free $\mathrm{Hb}$ and hemolysis rates were not significantly different between the 150 and 300 mmHg conditions and between the 3 different suction tips $(\mathrm{P}>$ 0.05 , Table 1 ). The free $\mathrm{Hb}$ and hemolysis rate were significantly 
A

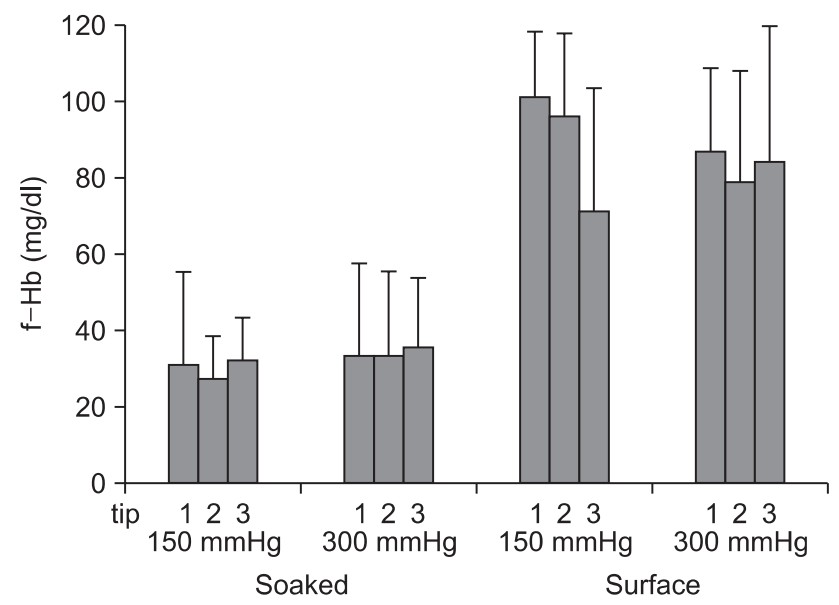

B

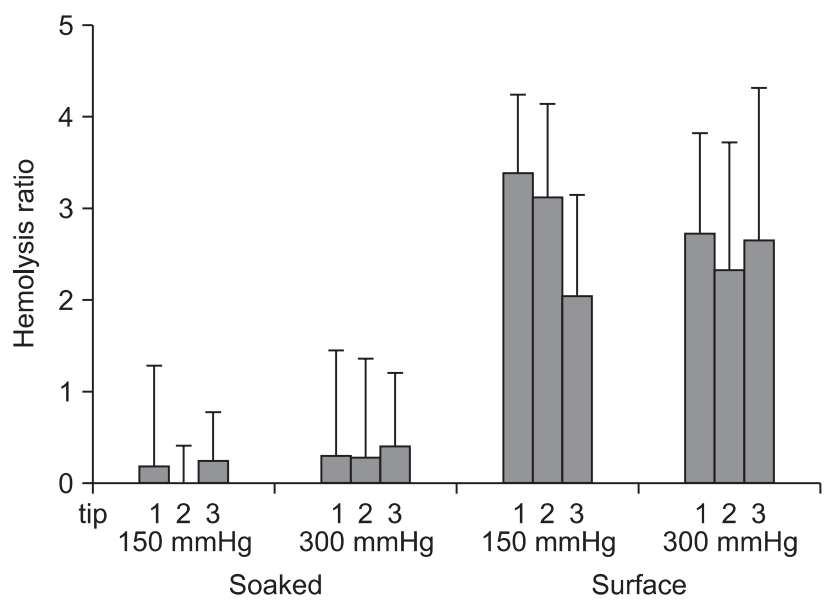

Fig. 3. Free hemoglobin production and the hemolysis rate after suction. The size and shape of suction tips 1, 2 and 3 are depicted in Fig. 2. Error bars are the standard deviation. (A) More than twice as much free hemoglobin was produced with the partially immersed suction tips than that with the completely immersed suction tips. The suction pressure and the size/shape of the suction tips did not influence the production of free hemoglobin. (B) Hemolysis was increased about 10 times more with the completely immersed suction tips than with the partially immersed suction tips. The suction pressure and the size/shape of the suction tips did not influence the hemolysis rate.

Table 1. Free Hemoglobin Production Profile Based on the Suction Pressure, Different Suction Tips and the Immersion Conditions of the Suction Tips

\begin{tabular}{lcccc}
\hline \multicolumn{1}{c}{ Suction condition } & Free $\mathrm{Hb}(\mathrm{mg} / \mathrm{dl})$ & Hemolysis ratio (\%) & Total Hb (g/d) & Hematocrit (\%) \\
\hline $150 \mathrm{mmHg}$ & $60.4 \pm 37.1$ & $1.5 \pm 1.7$ & $13.0 \pm 1.2$ & $38.2 \pm 3.4$ \\
$300 \mathrm{mmHg}$ & $59.0 \pm 35.1$ & $1.5 \pm 1.6$ & $13.1 \pm 1.0$ & $38.5 \pm 2.8$ \\
Suction tip 1 & $63.6 \pm 38.0$ & $1.7 \pm 1.8$ & $13.7 \pm 1.0$ & $37.4 \pm 2.9$ \\
Suction tip 2 & $59.2 \pm 36.5$ & $1.4 \pm 1.7$ & $13.2 \pm 1.1$ & $38.9 \pm 3.1$ \\
Suction tip 3 & $56.2 \pm 34.0$ & $1.4 \pm 1.5$ & $13.3 \pm 1.1$ & $38.8 \pm 3.2$ \\
Completely immersed tip & $32.4 \pm 18.3$ & $0.2 \pm 0.9$ & $13.2 \pm 1.1$ & $39.1 \pm 3.2$ \\
Partially immersed tip & $71.6 \pm 37.4^{\dagger}$ & $2.0 \pm 1.6^{\dagger}$ & $38.8 \pm 3.2$
\end{tabular}

Each suction condition was defined under fixed conditions. For example, the "150 mmHg" condition indicated that the free hemoglobin productions with 3 different suction tips (1,2 and 3) and 2 immersion conditions (completely and partially immersed tips) were averaged in the "150 mmHg". Similarly, the "suction tip 1" condition indicated that the free hemoglobin productions with 2 suction pressures (150 mmHg, $300 \mathrm{mmHg}$ ) and 2 immersion conditions (completely and partially immersed tips) were averaged in the "suction tip 1". Values are expressed as means \pm SDs. *The size and shape of suction tips 1,2 and 3 are depicted in Fig. $2 .{ }^{\dagger}$ Free hemoglobin production and the hemolysis ratio were significantly higher with the partially immersed suction tips than that with the completely immersed suction tips. The other conditions caused no difference in free hemoglobin production and the hemolysis ratio.

different between the completely and partially immersed tips in all the combinations of other suction conditions $(\mathrm{P}<0.001$, Table 2). The free $\mathrm{Hb}$ and hemolysis rates were not significantly different between the 3 different suction tips and between the 150 and $300 \mathrm{mmHg}$ conditions in all the combinations of other suction conditions $(\mathrm{P}>0.05)$.

The total $\mathrm{Hb}$ and hematocrit were not significantly different in the all suction conditions, and the measurements were similar in the pre- and postsuction conditions.

\section{Discussion}

In this study, during blood salvage using an autotransfusion apparatus, contact of the suction tip with air had a significant effect on the production of free Hb. Previous studies on the independent factors have demonstrated that all 3 factors independently influence the production of free $\mathrm{Hb}[1,12,13]$. However, analysis of the combined suction conditions revealed that the negative suction pressure and the suction tip design did not exert any significant effect on the production of free $\mathrm{Hb}$, but that contact of a suction tip with air exerted a significant effect on the production of free $\mathrm{Hb}$ (the free $\mathrm{Hb}$ and hemolysis rate were increased by more than 2-fold when approximately half of the suction tip was exposed to air).

Unlike the previous studies, our study analyzed the effects of combined suction conditions on the production of free Hb. Previous studies have reported that each of the 3 suction conditions independently influences the production of free 
Table 2. Free Hemoglobin Production Profile Based on the 2 Combined Conditions of Suction Pressure, Different Suction Tips or the Immersion Conditions of the Suction Tips

\begin{tabular}{llcccc}
\hline Combined conditions & & Free Hb $(\mathrm{mg} / \mathrm{dl})$ & Hemolysis ratio & Total Hb (g/dl) & Hematocrit (\%) \\
\hline \multirow{2}{*}{$150 \mathrm{mmHg}$} & Completely immersed & $30.6 \pm 15.5$ & $0.2 \pm 0.7$ & $13.3 \pm 1.2$ & $39.1 \pm 3.4$ \\
& Partially immersed & $90.1 \pm 27.0^{\dagger}$ & $2.9 \pm 1.2^{\dagger}$ & $12.6 \pm 1.1$ & $37.2 \pm 3.1$ \\
$300 \mathrm{mmHg}$ & Completely immersed & $34.3 \pm 20.8$ & $0.3 \pm 1.0$ & $13.2 \pm 1.0$ & $39.0 \pm 3.0$ \\
$150 \mathrm{mmHg}$ & Partially immersed & $83.7 \pm 28.6^{\dagger}$ & $2.6 \pm 1.4^{\dagger}$ & $12.9 \pm 0.9$ & $38.0 \pm 2.6$ \\
& Suction tip 1* & $66.6 \pm 41.1$ & $1.8 \pm 1.9$ & $12.5 \pm 1.0$ & $36.7 \pm 3.1$ \\
& Suction tip 2 & $62.2 \pm 39.1$ & $1.6 \pm 1.8$ & $13.4 \pm 1.2$ & $39.3 \pm 3.3$ \\
$300 \mathrm{mmHg}$ & Suction tip 3 & $52.3 \pm 30.8$ & $1.1 \pm 1.2$ & $13.1 \pm 1.1$ & $38.5 \pm 3.4$ \\
& Suction tip 1 & $60.6 \pm 35.5$ & $1.5 \pm 1.7$ & $12.9 \pm 0.9$ & $38.0 \pm 2.7$ \\
Completely immersed & $56.1 \pm 34.4$ & $1.3 \pm 1.6$ & $13.0 \pm 1.0$ & $38.4 \pm 2.8$ \\
& Suction tip 2 & $60.2 \pm 37.2$ & $1.6 \pm 1.7$ & $13.3 \pm 1.0$ & $39.2 \pm 3.0$ \\
\multirow{5}{*}{ Partially immersed } & Suction tip 3 & $32.6 \pm 23.0$ & $0.2 \pm 1.1$ & $13.1 \pm 1.0$ & $38.5 \pm 3.0$ \\
& Suction tip 1 & $30.5 \pm 17.0$ & $0.2 \pm 0.8$ & $13.6 \pm 1.1$ & $39.9 \pm 3.2$ \\
& Suction tip 2 & $34.1 \pm 14.4$ & $0.3 \pm 0.7$ & $13.2 \pm 1.1$ & $39.9 \pm 3.3$ \\
& Suction tip 3 & $94.5 \pm 20.5^{\dagger}$ & $3.1 \pm 1.0^{\dagger}$ & $12.3 \pm 0.8$ & $36.3 \pm 2.5$ \\
& Suction tip 1 & $87.9 \pm 26.6^{\dagger}$ & $2.7 \pm 1.3^{\dagger}$ & $12.8 \pm 0.9$ & $37.9 \pm 2.6$ \\
& Suction tip 2 & $78.3 \pm 33.6^{\dagger}$ & $2.4 \pm 1.4^{\dagger}$ & $13.1 \pm 1.0$ & $39.8 \pm 3.0$ \\
\hline
\end{tabular}

Each suction condition was defined under fixed conditions. For example, the "150 mmHg completely immersed" condition indicated that the free hemoglobin productions with 3 different suction tips (1,2 and 3) were averaged in the "150 mmHg completely immersed." Similarly, "the soaked suction tip 1" condition indicated that the free hemoglobin production with 2 suction pressures (150 $\mathrm{mmHg}, 300 \mathrm{mmHg}) \mathrm{were}$ averaged. Values are expressed as means \pm SDs. *The size and shape of suction tips 1,2 and 3 are depicted in Fig. $2 .{ }^{\dagger}$ Free hemoglobin production and the hemolysis ratio were significantly higher with the partially immersed suction tips than with the completely immersed suction tips. The other conditions caused no difference in free hemoglobin production and the hemolysis ratio.

$\mathrm{Hb}$ and that there are slight increases of the free $\mathrm{Hb}$ depending on the experimental conditions. However, the results of those studies are subject to some limitations in that they compared measurements under certain varying suction conditions while the remaining suction conditions were set at constant levels. We also studied the effects of the 3 suction conditions on the production of free $\mathrm{Hb}$ with a similar design as that of the previous studies. In the experiment with suction tip-3 and the completely immersed suction tip, more free $\mathrm{Hb}$ was produced in the $300 \mathrm{mmHg}$ condition than in the $150 \mathrm{mmHg}$ condition (Table 1 and 2). In the partially immersed tip condition, the free $\mathrm{Hb}$ was $94.5 \pm 20.5 \mathrm{mg} / \mathrm{dl}$ with the suction tip-1 and 78.3 $\pm 33.6 \mathrm{mg} / \mathrm{dl}$ with the suction tip-3, which were higher than in the other suction conditions, but the differences were not significant (Table 2). Such differences were small compared to those between the completely and partially immersed suction tips (Fig. 3). Our results are consistent with those of a previous study that demonstrated that the free $\mathrm{Hb}$ was not increased even at a negative pressure of $400 \mathrm{mmHg}$ [14].

Our study has some limitations due to the use of stored blood rather than fresh blood. Stored blood usually causes more hemolysis than fresh blood. Hausen et al. [14] have suggested that the results of experiments using stored blood appear to be different from those using fresh blood. Further studies with a similar study design using fresh blood in a surgical setting are needed to confirm our results.

Although numerous studies on the production and side effects of free $\mathrm{Hb}$ have been widely conducted, there are no definite criteria for the appropriate level of free $\mathrm{Hb}$ in reinfused salvaged blood $[11,12,15]$. Therefore, the acceptable level of free $\mathrm{Hb}$ in blood collected using an autotransfusion apparatus should be determined by investigating the severity of side effects according to the free $\mathrm{Hb}$ levels.

Based on our results, different methods for collecting blood from the operative field can be used, depending on the quantity of the blood. When there are large quantities of blood, the blood can be safely collected by using immersed suction tips with an autotransfusion apparatus, which produces relatively little free $\mathrm{Hb}$. When there are small quantities of blood in the operative field, the blood can be safely collected by using another type of suction apparatus, or it can be collected by using surgical sponges. In clinical settings with small quantities of blood, a negative pressure of $150 \mathrm{mmHg}$ and a large suction tip are currently recommended for collecting the blood. However, based on our results, it is conceivable that this method appears to reduce the free $\mathrm{Hb}$ insufficiently.

In conclusion, the results of this study suggest that among the 3 suction conditions, including negative pressure, the kind of suction tip and contact of the suction tip with air, the last suction condition may have the most significantly influence on the production of free $\mathrm{Hb}$. Therefore, to minimize the production of free $\mathrm{Hb}$, it is better that an autotransfusion apparatus should be applied only when the operative field with large quantities of blood than that it is used with controlling the negative suction pressure or the use of large suction tip. 


\section{Conflicts of Interest}

The corresponding author is a consultant of ACE-medical, Royal medical. He is a former consultant of Korea Yansen, MEK-ics, etc.

\section{Acknowledgements}

The authors thank Eunju Seo for her thorough review of manuscript editing.

\section{References}

1. Waters J, Shander A. Perioperative blood management: A physician's handbooked. 2nd ed. Bethesda, American association of blood banks. 2009, pp 67-83.

2. Singbartl G, Schreiber J, Singbartl K. Preoperative autologous blood donation versus intraoperative blood salvage: intraindividual analyses and modeling of efficacy in 1103 patients. Transfusion 2009; 49: 2374-83.

3. Kim YJ, Baik HJ, Kim JH, Yu EY. Effect of Autotransfusion Using the Drained Blood after Bilaterla Total Knee Arthroplasty. Korean J Anesthesiol 2006; 51: 29-35.

4. Matsuda K, Nozawa M, Katsube S, Maezawa K, Kurosawa H. Activation of fibrinolysis by reinfusion of unwashed salvaged blood after total knee arthroplasty. Transfus Apher Sci 2010; 42: 33-7.

5. Matsuda K, Nozawa M, Katsube S, Maezawa K, Kurosawa H. Reinfusion of unwashed salvaged blood after total knee arthroplasty in patients with rheumatoid arthritis. Int Orthop 2009; 33: 1615-8.

6. Jeon SY, Bae JY, Na HS, Kim HS, Kim CS, Kim SD, et al. The Effect of Intraoperative Autotransfusion using a Continuous Autotransfusion System (CATS(R)) on for Homologous Transfusion in Children. Korean J Anesthesiol 2008; 54: 619-22.

7. Lee JH, Shin DH, Hoo GJ, Lee CH, Na CY. Cardiac surgeries without transfusion. Korean J Anesthesiol 2007; 52: 530-6.

8. Waters JR, Meier HH, Waters JH. An economic analysis of costs associated with development of a cell salvage program. Anesth Analg 2007; 104: 869-75.

9. Sloan TB, Myers G, Janik DJ, Burger EM, Patel VV, Jameson LC. Intraoperative Autologous Transfusion of Hemolyzed Blood. Anesth Analg 2009; 109: 38-42.

10. Nielsen MJ, Møller HJ, Moestrup SK. Hemoglobin and Heme Scavenger Receptors. Antioxid Redox Signal 2010; 12: 261-73.

11. Buehler PW, D'Agnillo F. Toxicological Consequences of Extracellular Hemoglobin: Biochemical and Physiological Perspectives. Antioxid Redox Signal 2010; 12: 275-91.

12. Gregoretti S. Suction-induced hemolysis at various vacuum pressures: Implications for intraoperative blood salvage. Transfusion 1996; 36: 57-60.

13. Nevaril CG, Lynch EC, Alfrey CP Jr, Hellums JD. Erythrocyte damage and destruction induced by shearing stress. J Lab Clin Med 1968; 71: 784-90.

14. Hansen E, Kling J, Roth G. The myth of suction pressure limitation in blood salvage. Anasth Intensivmed 2006; 47: S118-22.

15. Gueye PM, Bertrand F, Duportail G, Lessinger JM. Extracellular haemoglobin, oxidative stress and quality of red blood cells relative to perioperative blood salvage. Clin Chem Lab Med 2010; 48: 67783. 